\title{
Upregulation of GABA receptor promotes long-term potentiation and depotentiation in the hippocampal CA1 region of mice with type 2 diabetes mellitus
}

\author{
LI-LI TU $^{1 *}$, QIN SUN $^{2 *}$, LING-LING WEI ${ }^{2}$, JING SHI $^{2}$ and JIAN-PING LI ${ }^{1}$ \\ ${ }^{1}$ Department of Geratology, Sichuan Academy of Medical Sciences and Sichuan Provincial People's Hospital, \\ Chengdu, Sichuan 610072; ${ }^{2}$ Center of Diabetes Mellitus, School of Medicine, University of \\ Electronic Science and Technology of China, Chengdu, Sichuan 610000, P.R. China
}

Received July 17, 2018; Accepted April 18, 2019

DOI: $10.3892 /$ etm.2019.7868

\begin{abstract}
Type 2 diabetes mellitus (T2DM) is a long-term metabolic disorder characterized by high blood sugar levels, insulin resistance and a relative lack of insulin. A previous study has reported that an association exists between $\gamma$-aminobutyric acid (GABA) and the hippocampus. The current study therefore aimed to assess the effect of the GABA receptor (GABA-R) on the long-term potentiation (LTP) and depotentiation of the hippocampal CA1 region in mice with T2DM. Mice were divided into four groups: A normal group consisting of healthy mice and a GABA-R, negative control and blank group all comprising T2DM mice. The weight and blood glucose level of all mice were measured and GABA-R mRNA and protein expression were detected. A hydroxyl free radical (OH-) kit was used to determine the hippocampal $\mathrm{OH}$-content. Using an electrophysiological experiment, the population spike (PS) slope was observed every $5 \mathrm{~min}$. The results revealed that as GABA-R levels increased, the weight, blood glucose level and $\mathrm{OH}^{-}$content of the T2DM mice significantly decreased, and the neuron microstructures in the mice hippocampal tissue improved. The PS slope also significantly increased and the level of depotentiation improved. The results of the current study support the theory that the upregulation of GABA-R protects the neuronal ultrastructure and promotes LTP and depotentiation in the hippocampal CA1 region by inhibiting the accumulation of $\mathrm{OH}^{-}$in $\mathrm{T} 2 \mathrm{DM}$ mice.
\end{abstract}

Correspondence to: Dr Jian-Ping Li, Department of Geratology, Sichuan Academy of Medical Sciences and Sichuan Provincial People's Hospital, 32 West Second Section, First Ring Road, Qingyang, Chengdu, Sichuan 610072, P.R. China

E-mail: 1ijpcd@163.com

*Contributed equally

Key words: type 2 diabetes mellitus, $\gamma$-amino butyric acid receptor, long-term potentiation, depotentiation, hippocampal CA1 region

\section{Introduction}

Type 2 diabetes mellitus (T2DM) is a noninsulin-dependent chronic degenerative disease caused by defective insulin action and secretion that is characterized by metabolic complications and an abnormally high glucose level $(1,2)$. T2DM is a primary cardiovascular risk factor and is also considered a risk factor for coronary artery disease (3). Currently, T2DM is among the top three fatal diseases, alongside cancer and cardiovascular disease (4). Although controlling hyperglycemia is the aim of T2DM treatment, the underlying pathophysiology of T2DM is receiving increasing attention and is emerging as an important therapeutic target (5). The etiology of T2DM is associated with the destruction of pancreatic $\beta$-cell function, the induction of insulin resistance and the loss of $\beta$-cell mass (6). Genetic susceptibility also serves a critical role in the etiology and likelihood of developing T2DM and environmental factors likely to amplify genetic factors (7). It has been indicated that the $\gamma$-aminobutyric acid (GABA) signaling pathway is associated with T2DM (8).

GABA is the principle inhibitory neurotransmitter in the central nervous system (CNS) and serves an important role in the regulation of various psychological and physiological processes, including anxiety, depression and functional bowel disorders (9). The activation of GABA receptors (GABA-R) has been reported to inhibit obesity, high-fat diet-induced glucose intolerance and insulin resistance via an increase in $\mathrm{T}$ regulatory cell responses and the inhibition of obesity-associated inflammation in vivo, therefore intervening with T2DM (10). A previous study revealed no significant metabolite changes in the thalamus of diabetics but higher Glx/GABA levels in the right thalamus of those with diabetic neuropathy (11). A further study demonstrated that excitatory neurotransmitters (glutamate and glutamine) were increased and inhibitory neurotransmitters (GABA) were decreased in patients with T2DM, which is indicative of abnormal pain regulation (12). T2DM has been demonstrated to produce medical complications in several organ systems, including in the hippocampus (13). Furthermore, the association between glucose level and changes in cerebral metabolites have been previously reported (14). During the process of hippocampal 
formation, many neuromodulators are likely employed in synaptic plasticity, such as in long-term potentiation (LTP) induced by high-frequency stimulation (15). LTP is a long-lasting activity-dependent enhancement of the excitatory synapse, induced by brief high-frequent electrical stimulation and is generally considered to be the closest neural model of the learning and memory storage cellular mechanism, along with other forms of synaptic plasticity (16). T2DM is commonly associated with cognitive genetic decline, which can also create a burden to patients and their families (17). Impairment of LTP in the hippocampal CA1 region has been observed in a rat model of T2DM (18). Although it has been recently reported that insulin signaling modulates the activity of neurotransmitters, including inhibitory GABA-R, the underlying pathophysiological mechanisms are yet to be elucidated (19). Therefore, the current study was performed to assess the effects of GABA-R on hippocampal CA1 region depotentiation in T2DM mice.

\section{Materials and methods}

Study subjects and grouping. A total of 30 spontaneous T2DM mice (C57BLKS/J db/db; male; age, 9 weeks; weight, 34-38 g) at clean stage and 10 non-diabetic $\mathrm{db} / \mathrm{m}$ hetereozygous mice of the same age from the same brood were purchased from the Model Animal Research Center of Nanjing University (Nanjing, China) as negative control (NC). Mice in the NC group were treated with GABA-R-NC, whilst mice in the blank group received no treatment. During a 1-week quarantine in a specific pathogen free animal house, mice were housed in a temperature-controlled environment (humidity, 60-65\%; temperature, $21 \pm 3^{\circ} \mathrm{C}$ ) with a 12 -h light/dark cycle, and were provided free access to aseptic water and chow. $20 \mathrm{db} / \mathrm{db}$ mice were randomly assigned to the GABA-R or negative control (NC) groups (10 mice/group). A further 10 untreated $\mathrm{db} / \mathrm{db}$ mice were assigned to the blank group and the $10 \mathrm{db} / \mathrm{m}$ mice were assigned to the normal group. Mice in the GABA-R group were subsequently injected with a mixed solution of GABA-R gene plasmid (2 $\mu \mathrm{g}$; Shanghai GenePharma Co., Ltd.) and GeneJamer transfection agent (6 $\mu \mathrm{l}$; cat. no. 204130; Agilent Technologies, Inc.). Mice in the NC group were injected with a mixed solution consisting of the negative control plasmid pCMV6-AC-GFP (2 $\mu \mathrm{g}$; Shanghai GenePharma Co., Ltd.) and GeneJamer transfection agent $(6 \mu \mathrm{l})$. The plasmid and transfection agent mixture were injected directly into the hippocampal CA1 region of the GABA-R mice at a speed of $0.5 \mu \mathrm{l} / \mathrm{min}$ ) after an anesthetic intraperitoneal injection of pentobarbital sodium (45-50 $\mathrm{mg} / \mathrm{kg}$ ) (20). The process was repeated every five days for 30 days for a total of six injections. Mice were kept in separate cages at $23 \pm 1^{\circ} \mathrm{C}$ under a relative humidity of $50-60 \%$ under a 12 -h light/dark cycle with free access to food (standard rodent feed) and water. On day 30 after treatment, all mice were sacrificed and their brain tissues were utilized for subsequent experimentation $(21,22)$. The current study was performed with the approval of the Animal Ethics Committee of Sichuan Academy of Medical Sciences \& Sichuan Provincial People's Hospital (Chengdu, China). All animal experiments were performed in strict accordance with the Guide for the Care and Use of Laboratory Animal by International Committees.
Measurement of weight and blood glucose level. Mice were weighed using an analytical balance before and after treatment. During the process of blood collection, mice were fixed in position using a restraining device (cat. no. zk188; CHICO.J.X Environmental Protection Technology Co., Ltd.) to prevent rotation. One drop of blood was collected by puncturing the caudal vein using a syringe needle, which was then dropped into blood glucose test strips. Blood glucose level was measured using a micro blood glucose meter (Johnson \& Johnson) at 9 am before and after treatment.

Reverse transcription-quantitative PCR (RT-qPCR). On day 30 , four mice were randomly selected from the GABA-R, NC, blank and normal groups, and intraperitoneally injected with $1 \%$ pentobarbital sodium $(40 \mathrm{mg} / \mathrm{kg}$ ) for anesthesia. Following euthanasia, brain tissues were separated and the hippocampus was extracted. Total RNA in the right hippocampus was extracted using the TRIzol reagent (Thermo Fisher Scientific Inc.). The RNA sample (5 $\mu \mathrm{l})$ was diluted $20 \mathrm{X}$ with ultra-pure water without RNase. The optical density (OD) value was detected at 260 and $280 \mathrm{~nm}$ using an ultraviolet spectrophotometer to determine the concentration and purity of the RNA. RNAs with OD260/OD280 values between 1.7-2.1 were used for subsequent experiments. The cDNA template was obtained by reverse transcription using a PrimeScript ${ }^{\mathrm{TM}} \mathrm{RT}$ reagent kit (cat. no. RR047A; Takara Bio, Inc.) in a PCR amplification instrument. The reaction was performed at $37^{\circ} \mathrm{C}$ for $15 \mathrm{~min}$ and at $85^{\circ} \mathrm{C}$ for $5 \mathrm{sec}$. The ABI7500 qPCR instrument (cat. no. 4406985; Thermo Fisher Scientific Inc.) was utilized to perform the qPCR experiment using the EvaGreen ${ }^{\circledR}$ Dye (cat. no. 31000; Biotium, Inc.). The reaction conditions were as follows: Initial denaturation at $95^{\circ} \mathrm{C}$ for $10 \mathrm{~min}$, followed by 50 cycles of denaturation at $95^{\circ} \mathrm{C}$ for $15 \mathrm{sec}$ and annealing and elongation at $60^{\circ} \mathrm{C}$ for $1 \mathrm{~min}$. The following primers were used: GABA-R forward, 5'-TTCTAGCCTCCTTCCAGTATG ATTTG-3' and reverse, 5'-TACTCAACAGTACTGCTCCAC TTCC-3'; GAPDH forward, 5'-GATGGGTGTGAACCACG AGAAAT-3' and reverse, 5'-ACGGATACATTTGGGGGT AGGAA-3'. Each sample was measured three times and data was analyzed using the $2^{-\Delta \Delta C q}$ method (23).

Western blot analysis. Total protein was extracted using a RIPA lysis buffer (cat. no. P0013C; Beyotime Biotechnology Co., Ltd.) and the Bradford method (24) was used to perform protein quantification. Extracted protein $(50 \mu \mathrm{g})$ was separated by $7 \%$ SDS-PAGE and subsequently transferred to a PVDF membrane (EMD Millipore; Merck KGaA). The membrane was then blocked in 5\% skimmed milk on a shaking table at $37^{\circ} \mathrm{C}$ for $1 \mathrm{~h}$ and incubated with primary rabbit anti-mouse antibodies against GABA-R (1:1,000; cat. no. ab86497; Abcam) and $\beta$-actin $(1: 1,000$; cat. no. ab179467; Abcam) overnight at $4^{\circ} \mathrm{C}$. After washing with PBS supplemented with $0.05 \%$ Tween-20 three times (5 min/wash), the membrane was incubated with a horseradish peroxidase labeled goat anti-rabbit IgG antibody (1:2,000; cat. no. ab97051; Abcam) at room temperature for $2 \mathrm{~h}$. Membranes were subsequently washed and supplemented with electrogenerated chemiluminescence solution (GE Healthcare). After being developed with the X-ray film, protein bands were visualized using a Bio-Rad image analysis system (Bio-Rad Laboratories, Inc.). 
The relative content of the protein was expressed as a ratio of the target protein OD value to that of the $\beta$-actin band using the Quantity One software (v4.6.2; Bio-Rad Laboratories Inc.).

Transmission electron microscopy. Murine hippocampi were prefixed in $4 \%$ glutaraldehyde for $5 \mathrm{~h}$ at $4^{\circ} \mathrm{C}$, fixed in $1 \%$ Osmic acid for $2 \mathrm{~h}$ at $4^{\circ} \mathrm{C}$, infiltrated using epoxy resin and embedded. Specimens were cut into serial ultrathin sections (60-70 nm) using an LKB-V type ultrathin slicing machine (GE Healthcare). Sections were stained with $3 \%$ uranyl acetate and lead citrate at room temperature for $2 \mathrm{~min}$, photographed and observed under a HITACHI H-600 transmission electron microscope (magnification, x400; Hitachi, Ltd.).

Measurement of hydroxyl (OH-) free radicals in the hippocampus. The $\mathrm{OH}-$ content of the hippocampus was tested using an OH-detection kit (cat. no. A018-1-1; Nanjing Jiancheng Bioengineering Institute) in accordance with the manufacturers protocol. Samples were then allowed to rest at room temperature for $20 \mathrm{~min}$ and the OD value was measured at $550 \mathrm{~nm}$ to calculate $\mathrm{OH}$ - content $(\mathrm{U} / \mathrm{mg})$.

Electrophysiological experiment. Following anesthesia with sodium pentobarbital, mice hippocampus tissues were removed and cut into ultrathin sections $(60-70 \mathrm{~nm})$. Sections were then incubated in artificial cerebrospinal fluid (cat. no. 597316; Friends Honesty Life Sciences Co., Ltd.) for $1.5 \mathrm{~h}$ at $25^{\circ} \mathrm{C}$. A bipolar stimulating electrode was placed on the Schaffer collateral in the hippocampal CA3 region and a glass electrode was placed on the pyramidal cell layer in the hippocampal CA1 region to record the population spikes (PS). A basal PS was induced with medium intensity stimulation. After stabilization for $10 \mathrm{~min}$, the PS was adjusted to $50-60 \%$ of the maximum slope and kept stable for $15 \mathrm{~min}$. Then, the Schaffer collateral was stimulated by a $100 \mathrm{~Hz}$ high-frequency stimulation (HFS; 100 strings) to induce LTP. Data was continuously recorded for $60 \mathrm{~min}$. Finally, two sets of high-intensity paired-pulse low-frequency stimulations were delivered to depotentiate the LTP. Results were continuously recorded for $110 \mathrm{~min}$. The PS slope (\%) was recorded every $5 \mathrm{~min}$, as previously described (25).

Statistical analysis. All data were processed using the statistical software SPSS 21.0 (IBM Corp.). All measurement data were expressed as the mean \pm standard deviation. The weight and blood sugar levels before and after treatment of the two groups were compared using a paired Student's t-test. One-way ANOVA was used to compare data among multiple groups, followed by Tukey's post-hoc test. The comparison of the indexes of each group at different time points was measured via repeated-measure variance analyses. $\mathrm{P}<0.05$ was considered to indicate a statistically significant result.

\section{Results}

Upregulated GABA-R decreases the weight and blood glucose level of T2DM mice. Before treatment, the weights of mice in all groups exhibited no significant differences. After treatment in the GABA-R, NC, blank and normal groups, the weight and blood glucose levels in the normal group also exhibited no marked differences compared with those before treatment (all $\mathrm{P}>0.05$ ), whereas no significant differences were identified in the blood glucose level (all $\mathrm{P}>0.05$ ). Mice of the GABA-R group exhibited a significantly increased weight and a significantly decreased blood glucose levels after treatment when compared with that before treatment. Compared with the blank group, mice of the GABA-R group exhibited decreased weight and blood glucose levels $(\mathrm{P}<0.05$; Table I).

GABA-R $m R N A$ and protein levels. RT-qPCR and western blot analysis was used to detect GABA-R mRNA and protein expression in each group, respectively. The results of the current study indicated that GABA-R mRNA and protein levels in the GABA-R, NC and blank groups decreased compared with the normal group $(\mathrm{P}<0.05$; Fig. 1A and $\mathrm{B})$. Compared with the blank group, the mRNA and protein level of GABA-R in the NC group were not markedly different ( $\mathrm{P}>0.05$; Fig. 1A and B). However, the GABA-R group exhibited an increase in GABA-R mRNA and protein levels compared with the blank group $(\mathrm{P}<0.05$; Fig. $1 \mathrm{~A}$ and $\mathrm{B})$. Based on these results, the current study concluded that in vivo transfection increased the expression of GABA-R in murine hippocampal CA1 regions.

Upregulated GABA-R alleviates the pathological changes in the hippocampal $C A 1$ region of T2DM mice. Transmission electron microscopy was performed to observe the neuronal microstructure of mice hippocampi CA1 in each group (Fig. 2). The normal group exhibited a regular neuronal shape, smooth nuclear membranes, well-distributed chromatin, and numerous rough endoplasmic reticulum (RER) with ribosomes attached to the surface. The hippocampal neurons of the blank and NC groups exhibited displaced vacuoles in the cytoplasm, disintegration and maldistribution of chromatin in the nucleus, an expanding RER and degranulation. A nearly regular neuronal shape, decreased vacuoles in the cytoplasm, and slight expanding of the partial RER was observed in the GABA-R group compared with those in the blank group. The results demonstrate that GABA may alleviate lesions in the hippocampus CAI region of T2DM mice.

Upregulated GABA-R reduces the OH-content in the hippocampus in T2DM mice. The hippocampal $\mathrm{OH}-$ content was increased in the GABA-R, NC and blank groups compared with that in the normal group $(\mathrm{P}<0.05$; Fig. 3). Furthermore, compared with the blank group, the NC group revealed no marked difference $(\mathrm{P}>0.05)$, while the GABA-R group exhibited a significant decrease in hippocampal $\mathrm{OH}$ - content $(\mathrm{P}<0.05$; Fig. 3). These data demonstrate that $\mathrm{OH}$-content is decreased by upregulated GABA.

Upregulated GABA-R improves the decrease in hippocampal synaptic transmission efficiency of T2DM mice. The PS slope in the hippocampal CA1 region steadily increased with enhanced synaptic transmission intensity and efficiency after 60 min of HFS in the normal group. Although the PS slope in the GABA-R, NC and blank groups also increased, it was significantly lower than that in the normal group at the corresponding time points ( $\mathrm{P}<0.05$; Table II; Fig. 4). Compared with the blank group, the NC group revealed no marked differences 
Table I. Weight and blood glucose level of mice in all groups.

\begin{tabular}{|c|c|c|c|c|}
\hline \multirow[b]{2}{*}{ Groups } & \multicolumn{2}{|c|}{ Weight (g) } & \multicolumn{2}{|c|}{ Blood glucose $(\mathrm{mmol} / \mathrm{l})$} \\
\hline & Before & After & Before & After \\
\hline Normal & $35.34 \pm 3.02$ & $36.16 \pm 3.03$ & $9.43 \pm 0.95$ & $9.56 \pm 0.97$ \\
\hline Blank & $35.53 \pm 3.12$ & $47.33 \pm 3.79^{\mathrm{a}}$ & $25.46 \pm 4.23$ & $27.32 \pm 6.02$ \\
\hline Negative control & $35.39 \pm 3.04$ & $47.76 \pm 3.68^{\mathrm{a}}$ & $25.39 \pm 4.45$ & $27.93 \pm 6.29$ \\
\hline GABA-R & $35.89 \pm 3.97$ & $41.74 \pm 3.93^{\mathrm{a}, \mathrm{b}}$ & $25.37 \pm 4.17$ & $19.14 \pm 5.03^{\mathrm{a}, \mathrm{b}}$ \\
\hline
\end{tabular}

${ }^{\mathrm{a}} \mathrm{P}<0.05$ vs. the condition before treatment; ${ }^{\mathrm{b}} \mathrm{P}<0.05$ vs. the normal group after treatment. GABA-R, $\gamma$-aminobutyric acid receptor.
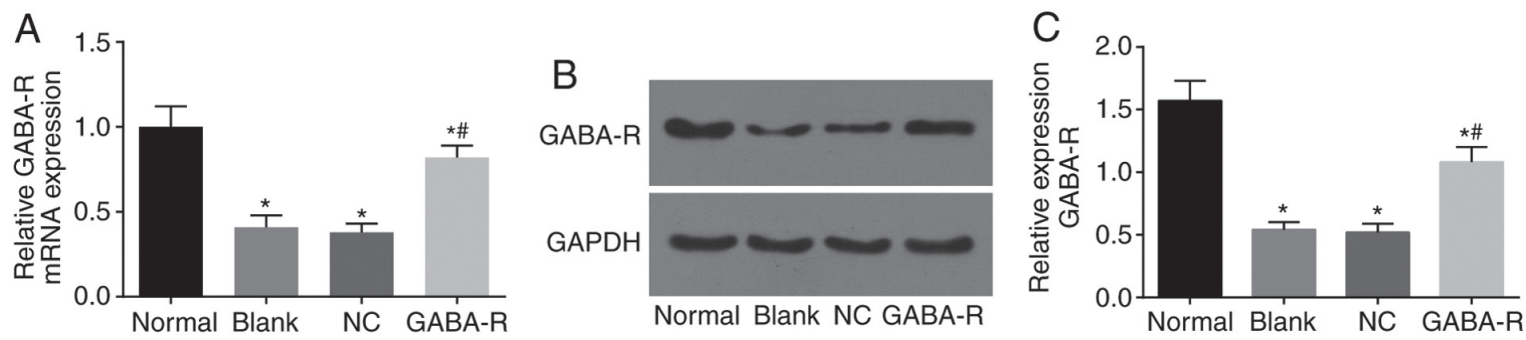

Figure 1. GABA-R mRNA and protein expression in brain tissue is increased in the GABA-R group. GABA-R (A) mRNA (B) protein expression in brain tissue from mice in the four groups with $(\mathrm{C})$ subsequent quantification. $\mathrm{P}<0.05$ vs. the normal group; ${ }^{\#} \mathrm{P}<0.05$ vs. the blank group. GABA-R, $\gamma$-aminobutyric acid receptor; $\mathrm{NC}$, negative control.

(P>0.05; Table II; Fig. 4), while the GABA-R group exhibited a significant increase in PS slope at the corresponding time points $(\mathrm{P}<0.05$; Table II; Fig. 4). These results indicate that the upregulation of GABA-R expression promotes a decrease in the hippocampal synaptic transmission efficiency in T2DM mice.

Upregulated GABA-R enhances depotentiation in the hippocampal CA1 region after LTP in T2DM mice. High-intensity paired-pulse low frequency stimulation was delivered after LTP for $60 \mathrm{~min}$ in the hippocampal CA1 region. LTP reversal in the normal group returned to the baseline level and the blank, NC and GABA-R groups all exhibited a partial reversal of LTP; however, the degree was less than that observed in the normal group ( $\mathrm{P}<0.05$; Table II; Fig. 4). Compared with the blank group, the $\mathrm{NC}$ group revealed no marked difference ( $\mathrm{P}>0.05$; Table II), while the GABA-R group exhibited more depotentiation ( $\mathrm{P}<0.05$; Table II; Fig. 4). Data from the current study therefore reveal that the overexpression of GABA-R promotes depotentiation in the hippocampal CA1 region after LTP in T2DM mice.

\section{Discussion}

The increase in T2DM global incidence has become an emerging health concern to people worldwide (26). The present study was performed to investigate the association between GABA-R and T2DM. The results demonstrated that the upregulation of GABA-R protects the neuronal ultrastructure and promotes LTP and depotentiation in the hippocampal CA1 region of mice. This may be achieved via the accumulation of $\mathrm{OH}-$ being accumulated in T2DM mice.
The current study demonstrated that T2DM induced a decrease in GABA-R expression in the hippocampus of mice. Insulin signaling modulates GABA-R and T2DM are mainly associated with defects in insulin action $(2,27)$. A previous study has demonstrated that in a T2DM model, GABA levels were increased and this increase was linked to the role of brain glycogen in maintaining an appropriate ratio between inhibitory and excitatory neurotransmitters (28). Furthermore, GABA concentration in patients with T2DM has been reported to be increased, which may be associated with lower cognitive function (19).

In the current study, the results revealed that the weight, blood glucose level and hippocampus $\mathrm{OH}$ - content of the GABA-R, NC and blank groups were all increased compared with those in the normal group. Furthermore, compared with the blank group, the GABA-R group exhibited a decrease in weight, blood glucose level and hippocampal $\mathrm{OH}-$ content. GABA-R has been revealed to be strongly associated with insulin signaling (29). Excessive adipose tissue is also associated with insulin resistance and the administration of insulin serves an active role in glycemic control $(30,31)$. These results may provide an explanation for the increase in weight and blood glucose level observed in T2DM mice and the decrease in weight and blood glucose level after the upregulation of GABA-R in the current study. Wilding et al (32) demonstrated that most patients diagnosed with T2DM are overweight and that people with obesity are more likely to develop T2DM. The increase in blood glucose levels of the T2DM mice in the current study is consistent with a previous report indicating that insulin homeostasis defects lead to T2DM, resulting in an increase in blood glucose concentration (28). Furthermore, $\mathrm{OH}-$ content is associated with insulin resistance due to the 


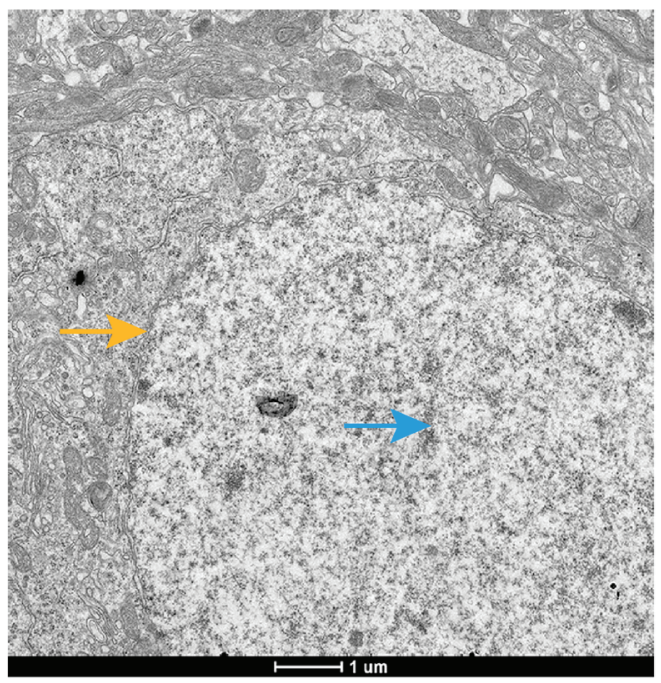

Normal

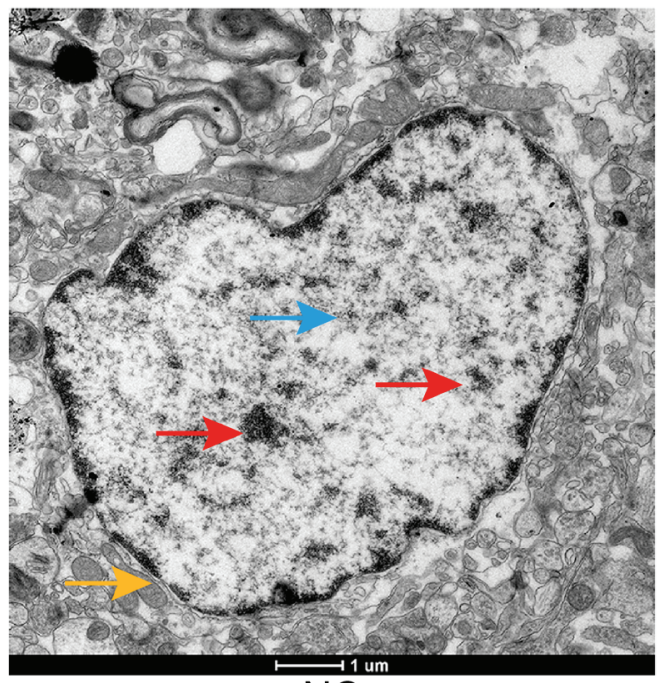

NC

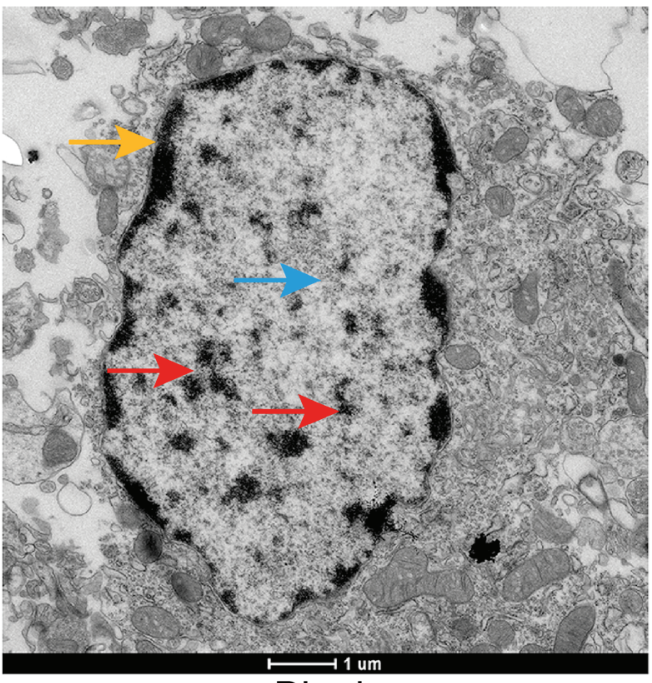

Blank

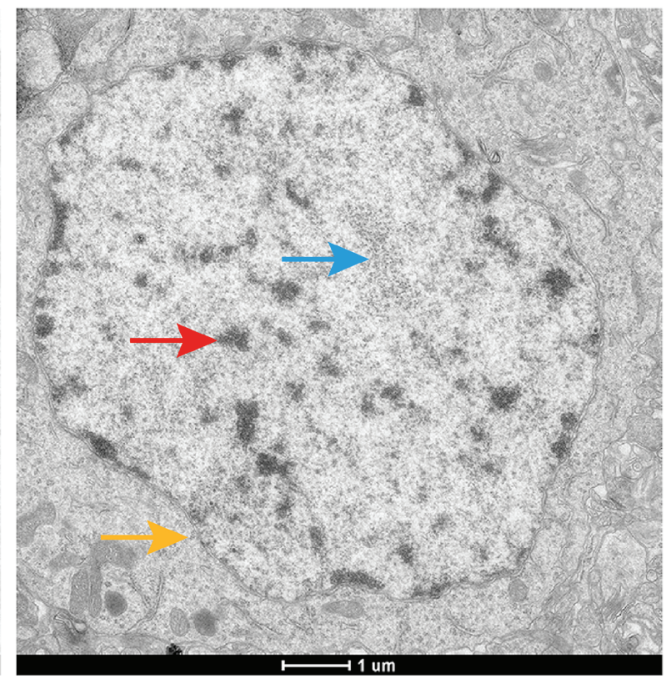

GABA-R

Figure 2. Upregulated GABA-R alleviates pathological changes in the hippocampal CA1 region of T2DM mice. Yellow arrows indicate nuclei; blue arrows indicate rough endoplasmic reticulum; red arrows indicate vacuoles. GABA-R, $\gamma$-aminobutyric acid receptor; T2DM, type 2 diabetes mellitus.

incorporation of ortho- and meta-tyrosine, and the OH- products of L-phenylalanine into cellular proteins, which leads to insulin resistance $(33,34)$. The link between $\mathrm{OH}$ - and insulin resistance may provide an explanation for the observation in the present study; that $\mathrm{OH}$ - content increases in T2DM mice and decreases after the upregulation of GABA-R. This result is consistent with a study performed by Molnár et al (35), who demonstrated that meta- and ortho-tyrosine may potentially interfere with insulin action. Additionally, the pathological change in the neuronal morphology in the GABA-R group of the current study decreased compared with that in the blank group. Due to its high reactivity, $\mathrm{OH}$ - reacts with macromolecules and yields oxidation products that induce damage to neurons via oxidative stress $(33,36)$. Therefore, the decrease in the $\mathrm{OH}$ - content observed in the present study may have led to the decrease in pathological changes of neuronal morphology in the GABA-R group due to the reduced possibility of oxidative stress. Molnár et al (35) indicated that a higher plasma level or urinary excretion of ortho- and

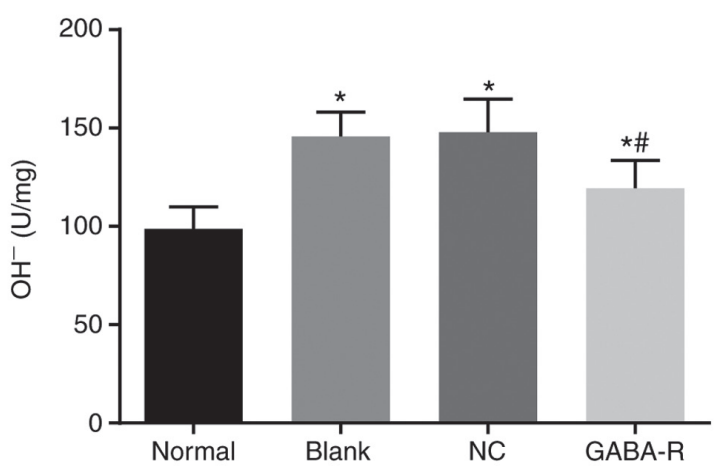

Figure 3. Measurement of $\mathrm{OH}^{-}$content in the hippocampus tissues of mice in each group. ${ }^{*} \mathrm{P}<0.05$ vs. the normal group; ${ }^{~} \mathrm{P}<0.05$ vs. the blank group. GABA-R, $\gamma$-aminobutyric acid receptor; $\mathrm{NC}$, negative control; $\mathrm{OH}^{-}$hydroxyl free radical.

meta-tyrosine, including hydroxylated phenylalanine derivatives, is associated directly with an alteration of the oxidative 
Table II. Changes in population spike slope in CAl region of hippocampal slices of mice in each group.

\begin{tabular}{|c|c|c|c|c|}
\hline Time & Normal & Blank & Negative control & GABA-R \\
\hline 0 & $101.14 \pm 13.12$ & $101.24 \pm 11.15$ & $102.14 \pm 11.34$ & $101.42 \pm 11.16$ \\
\hline 5 & $99.27 \pm 13.53$ & $102.61 \pm 11.98$ & $99.74 \pm 12.54$ & $99.97 \pm 11.74$ \\
\hline 10 & $100.11 \pm 14.62$ & $103.64 \pm 11.39$ & $100.63 \pm 12.43$ & $100.74 \pm 12.54$ \\
\hline 15 & $101.21 \pm 12.26$ & $105.65 \pm 11.79$ & $101.19 \pm 11.83$ & $101.21 \pm 12.29$ \\
\hline 20 & $210.32 \pm 20.24$ & $146.1 \pm 18.98^{\mathrm{a}}$ & $149.57 \pm 18.86^{\mathrm{a}}$ & $180.34 \pm 18.39^{\mathrm{a}, \mathrm{b}}$ \\
\hline 25 & $231.43 \pm 22.52$ & $163.34 \pm 20.57^{\mathrm{a}}$ & $161.41 \pm 21.73^{\mathrm{a}}$ & $195.18 \pm 22.97^{\mathrm{a}, \mathrm{b}}$ \\
\hline 30 & $239.31 \pm 23.24$ & $168.14 \pm 22.12^{\mathrm{a}}$ & $167.45 \pm 24.28^{\mathrm{a}}$ & $206.24 \pm 24.74^{\mathrm{a}, \mathrm{b}}$ \\
\hline 35 & $263.46 \pm 23.89$ & $205.67 \pm 24.74^{\mathrm{a}}$ & $204.76 \pm 26.45^{\mathrm{a}}$ & $232.12 \pm 26.36^{\mathrm{a}, \mathrm{b}}$ \\
\hline 40 & $265.21 \pm 33.41$ & $202.34 \pm 30.12^{\mathrm{a}}$ & $200.93 \pm 25.24^{\mathrm{a}}$ & $234.11 \pm 18.14^{\mathrm{a}, \mathrm{b}}$ \\
\hline 45 & $308.85 \pm 33.82$ & $242.35 \pm 27.43^{\mathrm{a}}$ & $240.19 \pm 27.39^{\mathrm{a}}$ & $271.26 \pm 30.28^{a, b}$ \\
\hline 50 & $312.63 \pm 33.29$ & $256.22 \pm 30.19^{\mathrm{a}}$ & $258.29 \pm 30.91^{\mathrm{a}}$ & $287.24 \pm 32.74^{\mathrm{a}, \mathrm{b}}$ \\
\hline 55 & $331.28 \pm 33.74$ & $252.19 \pm 32.59^{\mathrm{a}}$ & $255.43 \pm 31.91^{\mathrm{a}}$ & $294.32 \pm 35.57^{a, b}$ \\
\hline 60 & $333.64 \pm 35.97$ & $253.29 \pm 34.24^{\mathrm{a}}$ & $252.29 \pm 34.24^{\mathrm{a}}$ & $294.11 \pm 37.36^{\mathrm{a}, \mathrm{b}}$ \\
\hline 65 & $100.43 \pm 12.62$ & $167.57 \pm 18.6^{\mathrm{a}}$ & $164.73 \pm 18.83^{\mathrm{a}}$ & $137.44 \pm 17.91^{\mathrm{a}, \mathrm{b}}$ \\
\hline 70 & $99.98 \pm 11.74$ & $170.05 \pm 20.84^{\mathrm{a}}$ & $172.19 \pm 20.4^{\mathrm{a}}$ & $145.18 \pm 20.73^{a, b}$ \\
\hline 75 & $101.23 \pm 13.92$ & $187.45 \pm 20.68^{\mathrm{a}}$ & $188.83 \pm 20.84^{\mathrm{a}}$ & $151.24 \pm 20.44^{\mathrm{a}, \mathrm{b}}$ \\
\hline 80 & $100.21 \pm 12.64$ & $183.61 \pm 21.53^{\mathrm{a}}$ & $179.16 \pm 23.36^{\mathrm{a}}$ & $149.52 \pm 20.63^{a, b}$ \\
\hline 85 & $98.37 \pm 12.26$ & $207.64 \pm 23.14^{\mathrm{a}}$ & $210.34 \pm 23.53^{\mathrm{a}}$ & $175.31 \pm 19.04^{\mathrm{a}, \mathrm{b}}$ \\
\hline 90 & $100.87 \pm 12.94$ & $215.64 \pm 23.29^{\mathrm{a}}$ & $218.94 \pm 24.75^{\mathrm{a}}$ & $189.26 \pm 20.28^{a, b}$ \\
\hline 95 & $101.93 \pm 12.85$ & $226.52 \pm 23.42^{\mathrm{a}}$ & $229.04 \pm 25.26^{\mathrm{a}}$ & $193.24 \pm 21.74^{\mathrm{a}, \mathrm{b}}$ \\
\hline 100 & $101.21 \pm 12.43$ & $231.05 \pm 26.81^{\mathrm{a}}$ & $236.54 \pm 25.17^{\mathrm{a}}$ & $198.32 \pm 23.57^{\mathrm{a}, \mathrm{b}}$ \\
\hline 105 & $103.02 \pm 12.12$ & $242.01 \pm 23.43^{\mathrm{a}}$ & $247.3 \pm 23.33^{\mathrm{a}}$ & $203.29 \pm 23.36^{\mathrm{a}, \mathrm{b}}$ \\
\hline 110 & $101.98 \pm 12.92$ & $253.37 \pm 27.75^{\mathrm{a}}$ & $250.42 \pm 23.64^{\mathrm{a}}$ & $206.14 \pm 23.03^{\mathrm{a}, \mathrm{b}}$ \\
\hline
\end{tabular}

${ }^{\mathrm{a}} \mathrm{P}<0.05$ vs. the normal group at the same time point; ${ }^{\mathrm{b}} \mathrm{P}<0.05$ vs. the blank group at the same time point. GABA-R, $\gamma$-aminobutyric acid receptor.

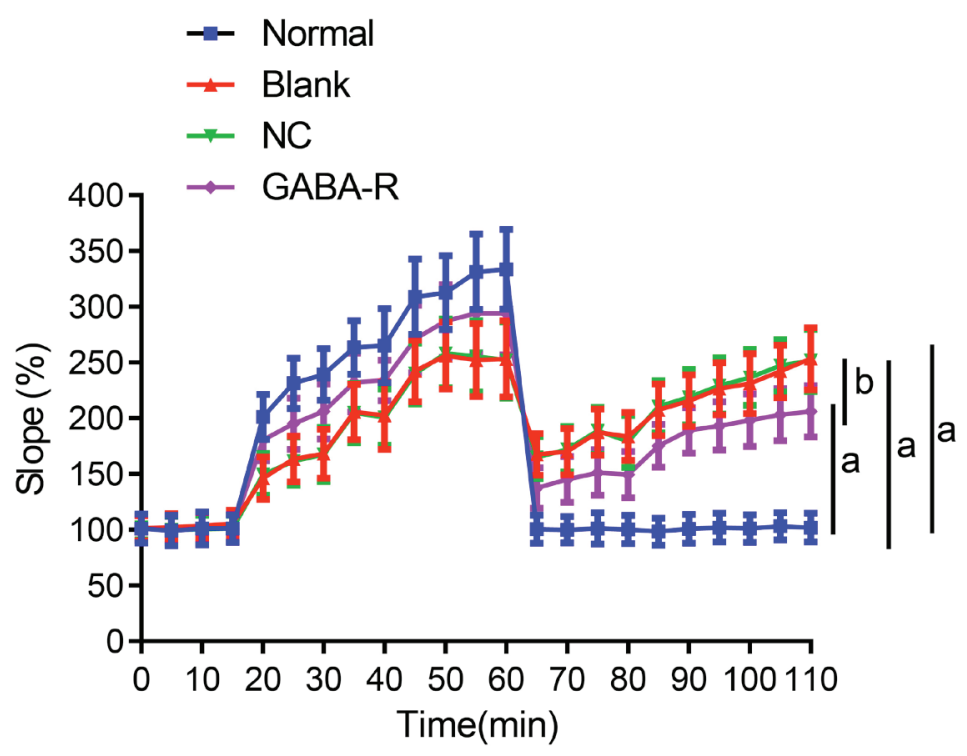

Figure 4. Changes in population spike slope in $\mathrm{CAl}$ region of hippocampal slices of mice in each group. ${ }^{\mathrm{a}} \mathrm{P}<0.05$ vs. the normal group at the same time point; ${ }^{\mathrm{b}} \mathrm{P}<0.05$ vs. the blank group at the same time point. GABA-R, $\gamma$-aminobutyric acid receptor.

state, thus serving as markers of oxidative stress, which serves a significant role in the pathogenesis of several morbidities including diabetic nephropathy.
The current study revealed that after LTP was induced, the PS slope in the GABA-R, NC and blank groups all decreased compared with the normal group, while the GABA-R group 
exhibited an increase in PS slope compared with the blank group. During depotentiation, LTP reversal in the normal group returned to the baseline level, but a partial reversal of LTP was observed in the blank, NC and GABA-R groups. Furthermore, the GABA-R group exhibited more depotentiation than the blank group. These results indicate that GABA-R upregulation promoted the efficacy of LTP and improved depotentiation in T2DM mice. T2DM has been proven to be associated with cognitive dysfunction (14). Cognitive impairments are widely believed to result from the progressive disruption of synaptic function and neurodegeneration triggered by aggregated amyloid- $\beta$, which contributes to the impairment of LTP $(16,18)$. However, GABA is the principal CNS inhibitory neurotransmitter and upregulated GABA-R may exhibit an active influence on synaptic plasticity, which also contributes to the increase in the PS slope after the upregulation of GABA-R $(9,19)$.

In conclusion, the present study assessed the effects of GABA-R upregulation on the weight, blood glucose level, accumulation of $\mathrm{OH}-$, neuronal ultrastructure, LTP and reversal LTP in T2DM mice. Ultimately, the data revealed that the upregulation of GABA-R serves an active role in LTP and depotentiation in the hippocampal CA1 region in T2DM mice. However, GABA-Rs can also be divided into GABA-A receptors, GABA-B receptors and GABA-C receptors, according to their different pharmacological characteristics (37) and the present study did not assess these specific types. Thus, further studies are necessary to confirm the results obtained in the present study.

\section{Acknowledgements}

The experiments were performed at the Cloud-Clone Corp (Wuhan, China).

\section{Funding}

The present study was supported by The Youth Training Program of Sichuan Provincial Science and Technology Department (grant no. 2016049).

\section{Availability of data and materials}

The datasets used and/or analyzed during the present study are available from the corresponding author upon reasonable request.

\section{Authors' contributions}

LT and QS designed the study. LT and LW collated the data, designed and developed the database, JS and JL performed the data analyses and produced the initial draft of the manuscript. JS, JL and LT drafted the manuscript. All authors have read and approved the final submitted manuscript.

\section{Ethics approval and consent to participate}

The current study was performed with the approval of the Animal Ethics Committee of Sichuan Academy of Medical Sciences \& Sichuan Provincial People's Hospital (Chengdu,
China). All animal experiments were performed in strict accordance with the Guide for the Care and Use of Laboratory Animal by International Committees.

\section{Patient consent for publication}

Not applicable.

\section{Competing interests}

The authors declare that they have no competing interests.

\section{References}

1. Alharbi KK, Khan IA, Munshi A, Alharbi FK, Al-Sheikh Y and Alnbaheen MS: Association of the genetic variants of insulin receptor substrate 1 (IRS-1) with type 2 diabetes mellitus in a Saudi population. Endocrine 47: 472-477, 2014

2. DeFronzo RA: Pharmacologic therapy for type 2 diabetes mellitus. Ann Intern Med 131: 281-303, 1999

3. O'Keefe JH, Abuannadi M, Lavie CJ and Bell DS: Strategies for optimizing glycemic control and cardiovascular prognosis in patients with type 2 diabetes mellitus. Mayo Clin Proc 86: 128-138, 2011.

4. Wang J, Huang Y, Li K, Chen Y, Vanegas D, McLamore ES and Shen Y: Leaf Extract from lithocarpus polystachyus rehd. Promote glycogen synthesis in T2DM mice. PLoS One 11: e0166557, 2016.

5. Zinman B: Initial combination therapy for type 2 diabetes mellitus: Is it ready for prime time? Am J Med 124 (Suppl 1): S19-S34, 2011.

6. Alonso-Magdalena P, Quesada I and Nadal A: Endocrine disruptors in the etiology of type 2 diabetes mellitus. Nat Rev Endocrinol 7: 346-353, 2011.

7. Adeghate E, Schattner P and Dunn E: An update on the etiology and epidemiology of diabetes mellitus. Ann N Y Acad Sci 1084: $1-29,2006$.

8. Taneera J, Jin Z, Jin Y, Muhammed SJ,Zhang E, Lang S, Salehi A, Korsgren O, Renström E, Groop L and Birnir B: $\gamma$-Aminobutyric acid (GABA) signalling in human pancreatic islets is altered in type 2 diabetes. Diabetologia 55: 1985-1994, 2012.

9. Bravo JA, Forsythe P, Chew MV, Escaravage E, Savignac HM, Dinan TG, Bienenstock J and Cryan JF: Ingestion of Lactobacillus strain regulates emotional behavior and central GABA receptor expression in a mouse via the vagus nerve. Proc Natl Acad Sci USA 108: 16050-16055, 2011

10. Tian J, Dang HN, Yong J, Chui WS, Dizon MP, Yaw CK and Kaufman DL: Oral treatment with gamma-aminobutyric acid improves glucose tolerance and insulin sensitivity by inhibiting inflammation in high fat diet-fed mice. PLoS One 6: e25338, 2011.

11. Petrou M, Pop-Busui R, Foerster BR, Edden RA, Callaghan BC, Harte SE, Harris RE, Clauw DJ and Feldman EL: Altered excitation-inhibition balance in the brain of patients with diabetic neuropathy. Acad Radiol 19: 607-612, 2012.

12. Santhakumari R, Reddy IY and Archana R: Effect of type 2 diabetes mellitus on brain metabolites by using proton magnetic resonance spectroscopy-a systematic review. Int J Pharma Bio Sci 5: 1118-1123, 2014

13. Hempel R, Onopa R and Convit A: Type 2 diabetes affects hippocampus volume differentially in men and women. Diabetes Metab Res Rev 28: 76-83, 2012.

14. Wang Y, Xu XY, Feng CH, Li YL, Ge X, Zong GL, Wang YB, Feng $\mathrm{B}$ and Zhang P: Patients with type 2 diabetes exhibit cognitive impairment with changes of metabolite concentration in the left hippocampus. Metab Brain Dis 30: 1027-1034, 2015.

15. Grassi S, Tozzi A, Costa C, Tantucci M, Colcelli E, Scarduzio M, Calabresi P and Pettorossi VE: Neural $17 \beta$-estradiol facilitates long-term potentiation in the hippocampal CA1 region. Neuroscience 192: 67-73, 2011.

16. Kumar A: Long-term potentiation at CA3-CA1 hippocampal synapses with special emphasis on aging, disease, and stress. Front Aging Neurosci 3: 7, 2011.

17. Abbatecola AM, Olivieri F, Corsonello A, Antonicelli R, Corica F and Lattanzio F: Genome-wide association studies: Is there a genotype for cognitive decline in older persons with type 2 diabetes? Curr Pharm Des 17: 347-356, 2011. 
18. Min JA, Lee HR, Kim JI, Ju A, Kim DJ and Kaang BK Impairment of long-term potentiation in the hippocampus of alcohol-treated OLETF rats. Neurosci Lett 500: 52-56, 2011.

19. van Bussel FC, Backes WH, Hofman PA, Puts NA, Edden RA van Boxtel MP, Schram MT, Stehouwer CD, Wildberger JE and Jansen JF: Increased GABA concentrations in type 2 diabetes mellitus are related to lower cognitive functioning. Medicine (Baltimore) 95: e4803, 2016.

20. Redfors B, Oras J, Shao Y, Seemann-Lodding H, Ricksten SE and Omerovic E: Cardioprotective effects of isoflurane in a rat model of stress-induced cardiomyopathy (takotsubo). Int J Cardiol 176 815-821, 2014.

21. Hitti FL and Siegelbaum SA: The hippocampal CA2 region is essential for social memory. Nature 508: 88-92, 2014.

22. Bathina S and Das UN: Dysregulation of PI3K-Akt-mTOR pathway in brain of streptozotocin-induced type 2 diabetes mellitus in Wistar rats. Lipids Health Dis 17: 168, 2018.

23. Livak KJ and Schmittgen TD: Analysis of relative gene expression data using real-time quantitative PCR and the 2(-Delta Delta $\mathrm{C}(\mathrm{T})$ ) method. Methods 25: 402-408, 2001

24. Carlsson N, Borde A, Wölfel S, Kerman B and Larsson A Quantification of protein concentration by the Bradford method in the presence of pharmaceutical polymers. Anal Biochem 411: $116-121,2011$

25. Bitiktaş S, Tan B, Kavraal Ş, Yousef M, Bayar Y, Dursun N and Süer C: The effects of intra-hippocampal L-thyroxine infusion on long-term potentiation and long-term depression: A possible role for the $\alpha v \beta 3$ integrin receptor. J Neurosci Res 95: 1621-1632, 2017.

26. Wu H, Zhong J, Yu M, Wang H, Gong W, Pan J, Fei F, Wang M, Yang L and Hu R: Incidence and time trends of type 2 diabetes mellitus in youth aged 5-19 years: A population-based registry in Zhejiang, China, 2007 to 2013. BMC Pediatr 17: 85, 2017.

27. Kleinridders A, Ferris HA, Cai W and Kahn CR: Insulin action in brain regulates systemic metabolism and brain function. Diabetes 63: 2232-2243, 2014.
28. Sickmann HM, Waagepetersen HS, Schousboe A, Benie AJ and Bouman SD: Brain glycogen and its role in supporting glutamate and GABA homeostasis in a type 2 diabetes rat model. Neurochem Int 60: 267-275, 2012.

29. Enell LE, Kapan N, Söderberg JA, Kahsai L and Nässel DR: Insulin signaling, lifespan and stress resistance are modulated by metabotropic GABA receptors on insulin producing cells in the brain of Drosophila. PLoS One 5: e15780, 2010.

30. Lee M and Aronne LJ: Weight management for type 2 diabetes mellitus: Global cardiovascular risk reduction. Am J Cardiol 99: 68B-79B, 2007.

31. Blevins T: Control of postprandial glucose levels with insulin in type 2 diabetes. Postgrad Med 123: 135-147, 2011.

32. Wilding JP: The importance of weight management in type 2 diabetes mellitus. Int J Clin Pract 68: 682-691, 2014.

33. Molnár GA, Mikolás EZ, Szijártó IA, Kun S, Sélley E and Wittmann I: Tyrosine isomers and hormonal signaling: A possible role for the hydroxyl free radical in insulin resistance. World J Diabetes 6: 500-507, 2015

34. Mikolás E, Kun S, Laczy B, Molnár GA, Sélley E, Kőszegi T and Wittmann I: Incorporation of ortho- and meta-tyrosine into cellular proteins leads to erythropoietin-resistance in an erythroid cell line. Kidney Blood Press Res 38: 217-225, 2013.

35. Molnár GA, Kun S, Sélley E, Kertész M, Szélig L, Csontos C, Böddi K, Bogár L, Miseta A and Wittmann I: Role of tyrosine isomers in acute and chronic diseases leading to oxidative stress-A review. Curr Med Chem 23: 667-685, 2016.

36. Kimura Y and Kimura H: Hydrogen sulfide protects neurons from oxidative stress. FASEB J 18: 1165-1167, 2004.

37. Cheng ZY, Chebib M and Schmid KL: Identification of GABA receptors in chick cornea. Mol Vis 18: 1107-1114, 2012.

(i) $\ominus$ This work is licensed under a Creative Commons

Attribution-NonCommercial-NoDerivatives 4.0 International (CC BY-NC-ND 4.0) License. 